\title{
Issue and Challenges of Reproductive Health Status of Rural Women in Kanchipuram District, Tamil Nadu
}

\author{
P. Sujatha ${ }^{1}$ and M. Rajeswari ${ }^{2}$ \\ ${ }^{1}$ Research Scholar, Centre for Rural Development, Annamalai University, Chidambaram, Tamil Nadu, India \\ ${ }^{2}$ Assistant Professor, Department of Economics, Annamalai University, Chidambaram, Tamil Nadu, India \\ E-Mail: sujatha2013phd@gmail.com
}

\begin{abstract}
The present research aimed to study the issue and challenges of reproductive health status of rural women in Kanchipuram district. Reproductive morbidity is a broad concept that encompasses health problems related to reproductive organs and functions, including and outside of childbearing360 samples were selected based on stratified random sampling method. In order to examine the economic factors related to health care services on reproductive health among selected respondents. Well-structured questionnaire were used for data collection. To test the hypotheses statistical tool such as F- test and t-test were used. There is need a wide scope for research to bring a holistic view of rural women health status. Since women faces various unique health issues as compared to male, there is a need for more specific and combined research on women health status. To analysis of issues and challenges of reproductive health status of rural women. Result found that respondents significantly differ in their issues and challenges on reproductive health status.

Keywords: Reproductive health status, Issues, Challenges, Rural, Women
\end{abstract}

\section{INTRODUCTION}

Human reproductive system is complex phenomenon, and a system it consists of vivid complicacy in term of health and health seeking related issues. Primarily the health related issues in context with reproductive health it refers to morbidity, life attributes and its quality and mortality attributes of individuals reproductive system. This process and is experienced by all women and men after certain period of life, especially after puberty. in comparison men women experience more issues related to reproductive health due to their having natural ability of becoming pregnant and going through all the process before and after pregnancy for example. Zurayk (1993) define reproductive health as "The ability of women to live through the reproductive years and beyond with reproductive choice, dignity, and successful childbearing, and be free of gynecological disease and risk". The international Conference on the Population and Development (ICPD, 1994) defined reproductive health in generic terms but stressed the importance of women's reproductive health.

Reproductive morbidity is a broad concept that encompasses health problems related to reproductive organs and functions, including and outside of childbearing. Reproductive morbidity can be broadly categorized into three subgroups: obstetric morbidity, gynecological morbidity includes health problems outside pregnancy such as RTIs, menstrual problems, cervical ectopic, infertility, cancers, prolepses and problems, related to intercourse. Contraceptive morbidity includes conditions, which result from efforts to limit fertility includes conditions, which result from efforts to limit fertility whether they are traditional or modern methods. Reproductive morbidity in general, is an outcome of not just biological factors but of women's poverty, powerlessness and lack of control over resources as will. Malnutrition, infection, early and repeated childbearing and high fertility also play an important role in poor maternal health conditions in India.

Indian's maternal mortality ratio (MMR) is highest in South Asia; 540 deaths per 100,000 live births or one women dying roughly every five minutes. An estimated 1,36,000 women die in India every year due to pregnancy related setbacks. The number of maternity- related deaths which occur in a week in India is equivalent to a whole year in Europe. However government has not taken any effective measuring till date. Despite the fact that an high fatalities occur among women in a year due to poor reproductive health practices no one is exercised enough to create a movement for improving women's health.

Reproductive health is explained as a state of complete physical, mental and social well-being and not merely the absence of diseases, in all matters relating to reproductive system. It is pertinent to point out the reproductive a satisfying and safe sex life and that they have the capability to reproduce and freedom to decide their reproductive choices. Further, reproductive health problems such as early and unwanted childbearing, HIV and other sexually transmitted infections, and pregnancy- related illness and death account for a significant part of the burden of disease among adolescents, adults and married of both sexes in developing countries. According to the World Development Report 2006, sexual and reproductive health, problems account of the burden among women of reproductive age. In other world, at least 18 percent of all disability adjusted life was caused by reproductive health problems.

Reproductive health problems are particularly concentrated among the poor who often lack access to minimum reproductive health care. As estimated 120 million wish to space and limit fertility but lack access to family planning (WDR, 2006), Prevention is the most-cost effective approach to addressing most reproductive health problems. 
Series problems are costly and very difficult to solve once manifest. The adverse consequences of poor reproductive health and the benefits of good reproductive health, extend well beyond health, and have an impact at the societal level. For example, early childbearing can have negative health and social consequences for young mothers and lasting health related effected on their children. On the other hand good reproductive health increases productivity and willbeing of the people, facility and ultimately the nation and world at large.

\section{REVIEW OF LITERATURE}

Goldani, (2002) Determined the trends of infant mortality from1995 to 1999 according to a maternal education in porto -alegre in Rio Grande do sul, Brazil, They found out that the IMR, decreased steadily from 18.38 deaths per 1000 live births in 1998to12.21 in 1999 (Chi-square from trend $\mathrm{p}$ $<0,001>$ ). Both neonatal and post -Neonatal mortality rates decreased although the drop seemed to be steeper for the Post -Neonatal component. The higher decline was seen in proper areas. This paper conducted that inequality in IMR seen to have decreased due to a steeper reduction in both neonatal and Post- Neonatal component of infant mortality in lower maternal schooling area.

Rajoice, (2012) this research has been taken to reproductive health status of Scheduled Caste married women, regarding in rural areas of Thiruvarur district of Tamil Nadu state. Multistage stratified random sampling technique was applied to select the respondent from the Thiruvarur district. There were 1164 households with the target population. Totally 1203 women in the age group of $15-25$ were identified in all the five blocks. A total of 605 respondents were selected by systematic random sampling Nearly threefifth of the scheduled cast women experienced any one kind of health problem during their pregnancy period (58.2 percent) and also half of the SC women experienced any one kind of delivery complication during their latest child delivery (49.4 percent). It is observed that education of women, standard of living condition, age at marriage and number of ANC visit was satisfactory significant with the prevalence of any one pregnancy related health problem among SC population.

\section{METHODOLOGY}

\section{A. Objective}

To analysis of issues and challenges of reproductive health status of rural women.

\section{B. Hypothesis}

1. There is no significant difference between issues and challenges for reproductive health status based on mode HIV/AIDS transfusion.

2. There is no significant difference between issues and challenges for reproductive health status based on health centre.
3. There is no significant difference between issues and challenges for reproductive health status based on pregnancy and breast feeding.

\section{Sampling}

360 samples were selected based on stratified random sampling method.

\section{Method of Data Collection}

Well-structured questionnaire were used for data collection.

\section{E. Statistical Tools Used}

Statistical tool such as F-test and t-test were used.

\section{RESULT AND DISCUSSION}

TABLE I SHOWING MEAN, S.D. AND F-VALUE FOR ESPONDENTS LEVEL OF ISSUES AND CHALLENGES FOR REPRODUCTIVE HEALTH STATUS BASED ON MODE HIV/AIDS TRANSFUSION

\begin{tabular}{|l|c|c|c|c|}
\hline $\begin{array}{c}\text { Mode HIV/AIDS } \\
\text { transfusion }\end{array}$ & Mean & S.D. & F-value & P-value \\
\cline { 1 - 3 } Sexual intercourse & 46.7 & 2.78 & & \\
\cline { 1 - 3 } Blood transfusion & 12.8 & 3.18 & \multirow{2}{*}{18.70} & $\begin{array}{c}0.001 \\
\text { Significant }\end{array}$ \\
\cline { 1 - 3 } All the above & 35.6 & 2.13 & & \\
\hline Don't know & 18.9 & 2.63 & & \\
\hline
\end{tabular}

Ho: There is no significant difference between issues and challenges for reproductive health status based on mode HIV/AIDS transfusion.

Result shows that the table I reveal the details of Mean, S.D. and F-value for respondents level of issues and challenges for reproductive health status based on mode HIV/AIDS transfusion. It is inferred from the obtained F-value there is a significant difference in respondent's level of issues and challenges for reproductive health status based on mode HIV/AIDS transfusion. Since the calculated F-value (18.70) which is significant at 0.001 level. Therefore the stated null hypothesis is rejected and alternate hypothesis is accepted. Therefore it is concluded that respondents differ in their level of issues and challenges for reproductive health status based on mode HIV/AIDS transfusion.

TABLE II SHOWING MEAN, S.D. AND F-VALUE FOR RESPONDENTS LEVEL OF ISSUES AND CHALLENGES FOR REPRODUCTIVE HEALTH STATUS BASED ON HEALTH CENTRE

\begin{tabular}{|l|c|c|c|c|}
\hline Health center & Mean & S.D & F-value & P-value \\
\hline Husband & 42.18 & 3.96 & & \\
\cline { 1 - 2 } Mother & 38.72 & 3.52 & & \\
\cline { 1 - 2 } Mother-in-low & 20.6 & 2.85 & \multirow{2}{*}{29.4} & $\begin{array}{c}0.001 \\
\text { Significant }\end{array}$ \\
\cline { 1 - 2 } Friends & 14.3 & 2.45 & & \\
\cline { 1 - 2 } Relatives & 26.8 & 3.60 & & \\
\hline Individual & 13.9 & 2.79 & & \\
\hline
\end{tabular}


Ho: There is no significant difference between issues and challenges for reproductive health status based on health centre.

It is inferred from the above table exhibits the details of Mean, S.D. and F-value for respondents level of issues and challenges for reproductive health status based on health centre. It is inferred from the obtained F-value there is a significant difference in respondent's level of issues and challenges for reproductive health status based on health centre.

Since the calculated F-value (29.4) which is significant at 0.001 level. Therefore the stated null hypothesis is rejected and alternate hypothesis is accepted. Therefore it is concluded that respondents differ in their level of issues and challenges for reproductive health status based on health centre.

TABLE III SHOWING MEAN, S.D. AND F-VALUE FOR
RESPONDENTS LEVEL OF ISSUES AND CHALLENGES FOR
REPRODUCTIVE HEALTH STATUS BASED ON
REPRODUCTIVE TRACT INFECTION
\begin{tabular}{|c|c|c|c|c|}
\hline $\begin{array}{c}\text { Reproductive } \\
\text { Tract } \\
\text { Infection }\end{array}$ & Mean & S.D. & F-value & P-value \\
\hline Yes & 34.63 & 4.18 & 18.7 & $\begin{array}{c}0.001 \\
\text { Significant }\end{array}$ \\
\hline No & 10.35 & 4.92 & & Signennn
\end{tabular}

Ho: There is no significant difference between issues and challenges for reproductive health status based on Reproductive Tract Infection.

It is observed from the above table exhibits the details of Mean, S.D. and F-value for respondent's level of issues and challenges for reproductive health status based on Reproductive Tract Infection. It is inferred from the obtained F-value there is a significant difference in respondent's level of issues and challenges for reproductive health status based on Reproductive Tract Infection.

Since the calculated F-value (18.7) which is significant at 0.001 level. Therefore the stated null hypothesis is rejected and alternate hypothesis is accepted. Therefore it is concluded that respondents differ in their level of issues and challenges for reproductive health status based on Reproductive Tract Infection.

\section{FINDINGS}

Based on the statistical analysis the following findings are arrived. They are

1. Analysis proved that respondents differ in their level of issues and challenges for reproductive health status based on mode HIV/AIDS transfusion.

2. Result shows that respondents differ in their level of issues and challenges for reproductive health status based on health centre.

3. Survey exhibits that respondents differ in their level of issues and challenges for reproductive health status based on Reproductive Tract Infection.

\section{CONCLUSION}

The present research aimed to study the issue and challenges of reproductive health status of rural women in Kanchipuram district. 360 samples were selected based on stratified random sampling method. In order to examine the economic factors related to health care services on reproductive health among selected respondents. Wellstructured questionnaire were used for data collection. To test the hypotheses statistical tool such as F- test and t-test were used. There is need a wide scope for research to bring a holistic view of rural women health status. The rural women health status of the women is discussed and found that the women health remains to be a challenging issue. There is a need of strong interrelationships between women health and development underscores the need to address the women reproductive health and its status. Result found that respondents significantly differ in their issues and challenges on reproductive health status.

\section{REFERENCES}

[1] Goldani. (2002). Narrowing in equality in infant mortality in Southern Brazil. Revista- de-saude-public. 36(4).

[2] ICPD. (1994). Symptoms of Reproductive Health Problems of Women in India. Demography India, 33(2), 231-248.

[3] Rajoice, et al. (2012). Reproductive health status- issues and concerns of tribal women. Journal of International Academic Research for Multidisciplinary Impact Factor, 2(1).

[4] WDR, (2006). The role of hydrology in the resolution of water disputes. Journal of Contemporary Water Research \& Amp Education Banner, 133(1), 17-25.

[5] Zurayk. (1993). Concepts and Measures of Reproductive Morbidity. Health Transition Review, 3(1), 17-39. 